\title{
Minimally Invasive Percutaneous Plate Osteosynthesis via a Deltoid- splitting Approach with Strut Allograft for the Treatment of Displaced 3- or 4-part Proximal Humeral Fractures
}

\author{
Young-Min Noh ${ }^{\circledR}$, Dong Ryul Kim, Chul-Hong Kim, Seung Yup Lee \\ Department of Orthopaedic Surgery, Dong-A University Hospital, 'Department of Shoulder Clinic, Mirae Hospital, Busan, Korea
}

Background: This study introduces a surgical technique with good clinical outcome useful in the treatment of osteoporotic displaced 3or 4-part proximal humeral fractures.

Methods: From May 2014 to February 2016, 16 patients with displaced 3- or 4-part proximal humeral fractures were treated by application of a locking plate with an endosteal strut allograft via a deltoid splitting approach with a minimum follow-up of 12 months. The allograft was inserted through a fractured gap of the greater tuberosity to support the humeral head and then fixed by a locking plate with meticulous soft tissue dissection to protect the axillary nerve. Surgical outcomes were evaluated by the American Shoulder and Elbow Surgeons (ASES) and visual analogue scale (VAS) scores, radiological imaging, and clinical examination. Fixation failure on radiographs was defined as a $>5^{\circ}$ loss of neck shaft angle (NSA) compared to that on an immediate postoperative radiograph. Avascular necrosis (AVN) of the humeral head was also evaluated.

Results: In all cases, complete union was achieved. The ASES and VAS scores were improved to $85.4 \pm 2.1$ and $3.2 \pm 1.3$, respectively. Twelve patients $(75.0 \%)$ had greater than a $5^{\circ}$ change in NSA; the average NSA change was $3.8^{\circ}$. Five patients (31.3\%) had unsatisfactory ranges of motion exhibiting a $<100^{\circ}$ active forward flexion. No axillary nerve injuries or AVN were observed at the last follow-up. One patient was converted to reverse total arthroplasty due to severe pain and functional deficit.

Conclusions: Minimally invasive fixation via a locking compression plate and an endosteal fibula strut allograft in Neer classification 3-or 4-part fractures with severe osteoporosis in elderly patients can achieve good clinical results.

(Clin Shoulder Elbow 2018;21(4):220-226)

Key Words: Shoulder fractures; Allografts; Fibula; Minimally invasive surgical procedures; Range of motion

\section{Introduction}

Proximal humerus fracture is reported to account for about $5 \%$ of limb fractures, and most of them are stable osteoporotic fractures in the elderly. ${ }^{1)}$ Moreover, most patients are reported to be able to regain a functional range of motion with non-surgical treatment. ${ }^{2)}$ A recent prospective comparative analysis showed that there is no better evidence of surgical fixation in displaced 3- or 4-part fractures in the elderly. ${ }^{3)}$ Surgical treatment is especially needed in patients who want improved shoulder function or who have severely comminuted fractures. ${ }^{4,5)}$ The purpose of surgical treatment is to prevent the progression of the displacement by obtaining a firm anatomical fixation, to prevent adhesion of the shoulder joint, and to improve the function by early exercise, ${ }^{6)}$ and various surgical methods have been suggested..$^{7-9)}$ Most elderly patients aged 65 years or older are accompanied by various medical problems including osteoporosis. Therefore, various methods of shortening the surgical time and the amount of bleeding while obtaining a firm fixation force have been proposed. ${ }^{10)}$ Recently, plate fixation with endosteal augmentation

Received May 28, 2018. Revised July 17, 2018. Accepted August 27, 2018.

Correspondence to: Young-Min Noh

Department of Orthopaedic Surgery, Dong-A University Hospital, 26 Daesingonwon-ro, Seo-gu, Busan 49201, Korea

Tel: +82-51-240-5166, Fax: +82-51-254-6757, E-mail: thugdoc@naver.com, ORCID: https://orcid.org/0000-0001-7149-7526

IRB approval: Dong-A University Hospital (DAUHIRB-18-126).

Financial support: None. Conflict of interests: None. 
using a fibula strut allograft has been reported to provide good medial support and good outcomes. ${ }^{11,12)}$ Most of the studies that have been reported have used the deltopectoral approach when performing fibula strut allograft augmentation. There has not yet been a description of fixation using a fibula strut allograft with deltoid split incisions and a locking compression plate applied through minimally invasive methods. Thus, the authors herein report on this useful method and the outcomes obtained in 16 patients.

\section{Methods}

\section{Patient Information}

We studied 16 patients diagnosed with severe osteoporosis who underwent surgery of a Neer classification 3- or 4-part fracture without humeral head dislocation. The mean age of the patients was 74.5 years (range, 63 to 81 years). The follow-up period was at least 1 year, and the mean follow-up period was 17.5 months (range, 12 to 28 months). The patients' preoperative mean bone mineral density was -3.2 (range, -4.1 to -2.6 ) (Table 1).

\section{Surgical Technique}

Surgery was performed at a mean of 4.2 days after injury. A minimally invasive method, minimally invasive percutaneous plate osteosynthesis (MIPPO) with two deltoid splitting incisions, was used (Fig. 1). While paying careful attention to possible axillary nerve injury, a longitudinal incision approximately 4-5 $\mathrm{cm}$ long was made to the anterolateral corner of the acromion, and the greater tuberosity fracture site was exposed through an interval between the anterior and middle portions of the deltoid. The fibula strut allograft was then inserted through the gap of the greater tuberosity into the bone marrow to the point at which it no longer entered (Fig. 2A, B). Authors insert the allograft through the medullary canal when it cannot be entered. Because the cannal size was smaller distally. So the remaining part of proximal portion was cut the appropriate size. If the canal is too small to insert the strut, a sagittal saw can be used to reduce its width prior to inserting it. In addition, if the strut bone is too long, its proximal portion located about $1 \mathrm{~cm}$ below the greater tuberosity level can be cut. A 2-0 Ethibond suture was then tagged on the rotator cuff and used for reduction of fracture fragments. After the insertion of the plate, temporary fixation with K-wire was performed. All patients were fixed with a locking compression plate (PHILOS ${ }^{\text {TM }}$ system; Depuy Synthes, West Chester, PA, USA) (Fig. 2C, D). We used fibula strut allograft in 15 cases and a radial strut allograft in one case. Care was taken to place the strut in a position that would not impinge on the acromion when inserting the plate. The plate screw was fixed to the subchondral bone so that it would not penetrate into the joint. In order to reinforce the medial support, an inferomedial screw was inserted, if possible. ${ }^{13)}$ In order to avoid axillary nerve

Table 1. Summary of Patient Characteristics

\begin{tabular}{|c|c|c|c|c|c|c|c|c|c|c|c|}
\hline $\begin{array}{l}\text { Case } \\
\text { No. }\end{array}$ & Sex & Age (yr) & Side & $\begin{array}{l}\text { Neer clas- } \\
\text { sification }\end{array}$ & $\begin{array}{c}\text { Injury } \\
\text { mechanism }\end{array}$ & $\begin{array}{c}\text { Preoperative } \\
\text { BMD }\end{array}$ & $\begin{array}{l}\text { Follow-up } \\
\text { period (mo) }\end{array}$ & $\begin{array}{l}\text { Last follow-up } \\
\text { ASES score }\end{array}$ & $\begin{array}{c}\text { Postoperative } \\
\text { neck shaft } \\
\text { angle }\left(^{\circ}\right)\end{array}$ & $\begin{array}{l}\text { Last follow-up } \\
\text { neck shaft } \\
\text { angle }\left(^{\circ}\right)\end{array}$ & $\begin{array}{l}\text { Last follow-up } \\
\text { VAS pain } \\
\text { score }\end{array}$ \\
\hline 1 & $\mathrm{~F}$ & 63 & $\mathrm{~L}$ & 4 & Car accident & -3.4 & 14 & 91 & 160 & 152 & 1 \\
\hline 2 & M & 66 & $\mathrm{~L}$ & 3 & Slip down & -2.6 & 28 & 92 & 159 & 160 & 2 \\
\hline 3 & $\mathrm{M}$ & 76 & $\mathrm{R}$ & 3 & Slip down & -2.9 & 12 & 88 & 158 & 155 & 3 \\
\hline 4 & $\mathrm{~F}$ & 72 & $\mathrm{R}$ & 3 & Car accident & -3.8 & 15 & 85 & 115 & 115 & 4 \\
\hline 5 & $\mathrm{~F}$ & 68 & $\mathrm{~L}$ & 3 & Car accident & -3.1 & 20 & 88 & 147 & 145 & 2 \\
\hline 6 & $\mathrm{~F}$ & 80 & $\mathrm{R}$ & 4 & Slip down & -4.1 & 12 & 58 & 117 & 98 & 8 \\
\hline 7 & $\mathrm{M}$ & 81 & $\mathrm{~L}$ & 4 & Slip down & -3.0 & 21 & 80 & 122 & 116 & 5 \\
\hline 8 & $\mathrm{M}$ & 77 & $\mathrm{~L}$ & 3 & Car accident & -2.8 & 14 & 82 & 120 & 120 & 3 \\
\hline 9 & $\mathrm{~F}$ & 78 & $\mathrm{R}$ & 3 & Slip down & -3.4 & 24 & 85 & 150 & 147 & 3 \\
\hline 10 & $\mathrm{~F}$ & 79 & $\mathrm{R}$ & 3 & Slip down & -2.7 & 19 & 83 & 120 & 119 & 3 \\
\hline 11 & M & 75 & $\mathrm{R}$ & 4 & Slip down & -2.8 & 17 & 87 & 140 & 132 & 2 \\
\hline 12 & $\mathrm{~F}$ & 75 & $\mathrm{~L}$ & 3 & Car accident & -3.5 & 16 & 92 & 128 & 128 & 3 \\
\hline 13 & $\mathrm{M}$ & 76 & $\mathrm{R}$ & 3 & Slip down & -3.6 & 13 & 90 & 157 & 158 & 3 \\
\hline 14 & $\mathrm{M}$ & 69 & $\mathrm{R}$ & 3 & Slip down & -2.7 & 26 & 89 & 112 & 110 & 5 \\
\hline 15 & $\mathrm{~F}$ & 79 & $\mathrm{~L}$ & 4 & Car accident & -3.1 & 14 & 88 & 144 & 147 & 2 \\
\hline 16 & $\mathrm{~F}$ & 78 & $\mathrm{~L}$ & 3 & Slip down & -3.8 & 15 & 89 & 152 & 155 & 3 \\
\hline
\end{tabular}

BMD: bone mineral density, ASES: American Shoulder and Elbow Surgeons, VAS: visual analogue scale, F: female, M: male, L: left, R: right. 

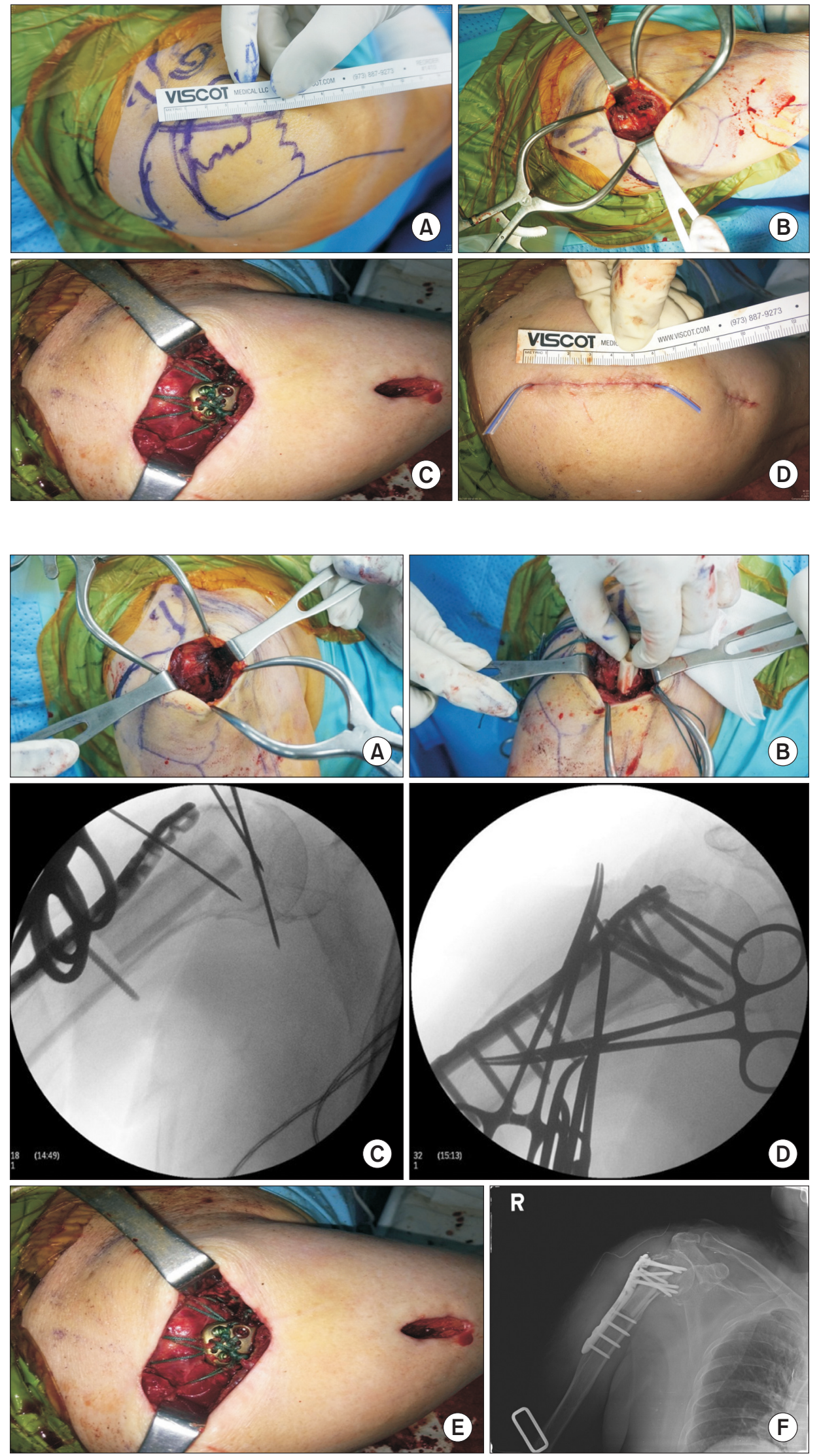

Fig. 1. Deltoid splitting approach using a minimally invasive percutaneous plate osteosynthesis technique. (A) A photograph at a distance from the anterolateral border of the acromion to prevent axillary nerve injury. (B) Image of the initial deltoid splitting incision. (C) Image of the two separated incisions after internal fixation was completed. (D) A photograph after the skin suturing was finished.

Fig. 2. The sequence of surgical techniques we used. Use of the deltoid-splitting approach (two separate incisions). (A) Fibula strut allograft was inserted through the fracture gap of the greater tuberosity. (B) After allograft insertion, the remnant bone was cut off at its proximal aspect. (C, D) Fracture site was reduced and the locking plate was positioned with temporary K-wire fixation. (E) Ethibond suturing was used to anchor the rotator cuff muscles to the locking plate. (F) Postoperative anteroposterior plain radiograph of the right shoulder. 
injury, an inferomedial screw was implanted with maximal abduction of the upper arm. The rotator cuff was tightly sutured to the plate by using a 2-0 Ethibond suture, and the plate was fixed using locking head screws (Fig. 2E). None of the cases had a rotator cuff tear, but if a small tear was suspected, the area was sutured to the plate.

\section{Postoperative Evaluation}

Simple radiographs were used to assess the degree of reduction and union of the fracture, the condition of the implant, and the presence of complications such as avascular necrosis of the humeral head. We performed radiographs immediately after surgery, as well as at 2 weeks, 6 weeks, 3 months, 6 months, and 12 months after surgery. Anteroposterior, lateral, and axillary view radiographs of the shoulder were obtained, and the neck shaft angle was measured by applying the Paavolainen method (Fig. 3). ${ }^{14)}$ American Shoulder and Elbow Surgeons (ASES) shoulder scores and visual analogue scale (VAS) pain scores were used for functional evaluation.

\section{Results}

Complete bone union was obtained in all cases (Fig. 4). Complications such as avascular necrosis of the humerus and axillary

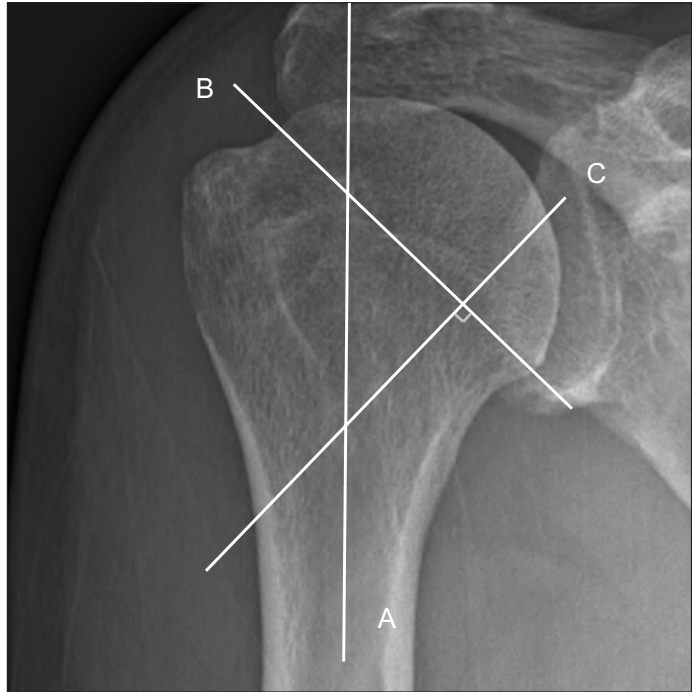

Paavolainen method

Fig. 3. Paavolainen method. Using an anteroposterior radiograph, the humeral neck shaft angle was determined by examining the intersection of a line drawn on the central axis of the humeral shaft (line A) with line $\mathrm{C}$ drawn perpendicular to the anatomical neck (line B) of the humerus (normal range: $\left.120^{\circ}-140^{\circ}\right)$
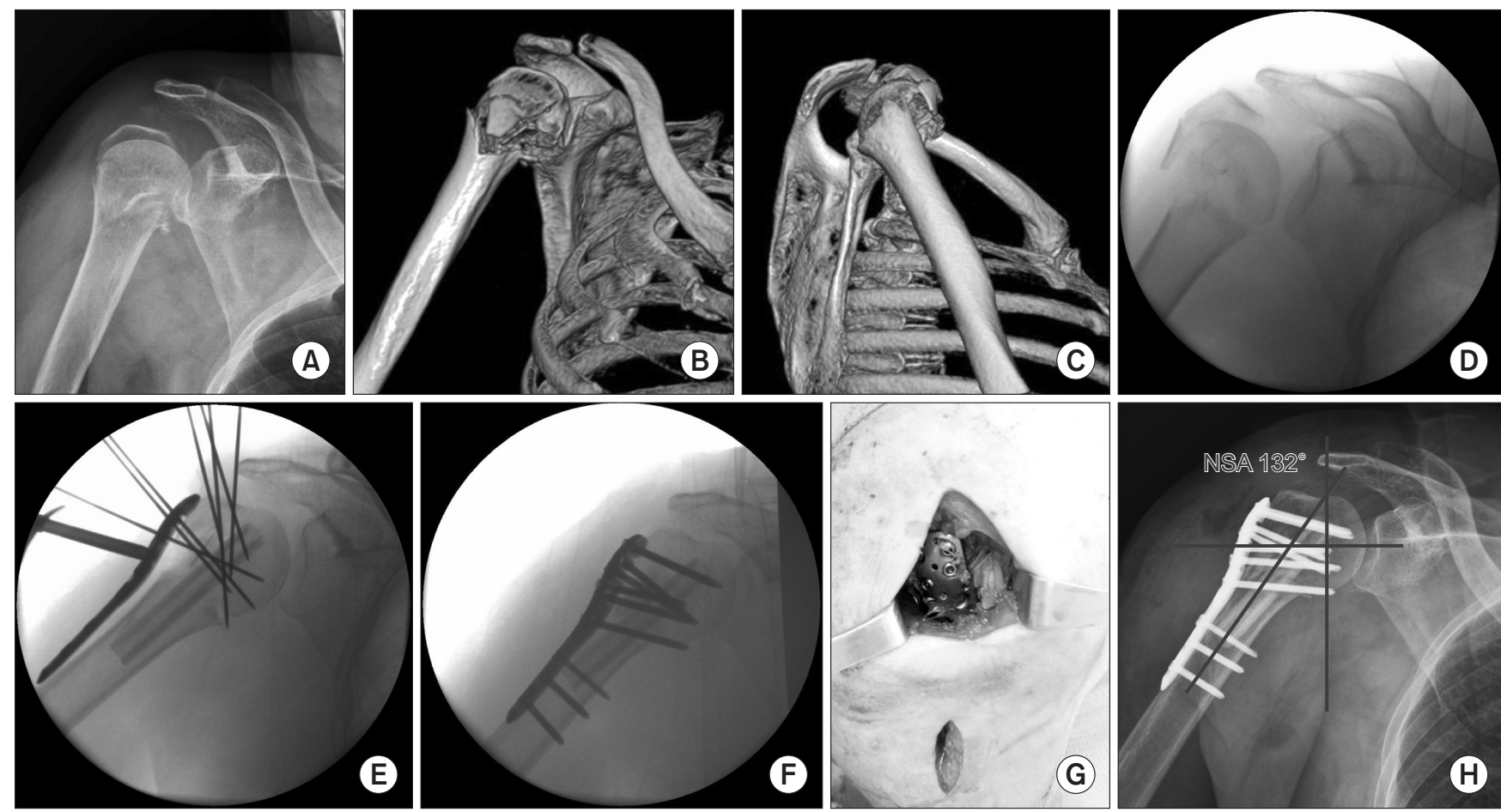

Fig. 4. A case of using our surgical technique. A 79-year-old woman whose bone mineral density score was -4.0 was injured in a pedestrian accident. (A) A plain radiograph shows a Neer classification 3-part proximal humeral fracture. (B, C) Three-dimensional computed tomography images show the same fracture. Using deltoid splitting incisions, a fibula strut allograft was inserted through the greater tuberosity fracture gap. (D, E) The locking plate was positioned with temporary K-wire fixation. (F) Definite fixation was accomplished. (G) The deltoid splitting incision and the fixated locking plate. (H) An anteroposterior view of the neck shaft angle (NSA) $\left(132^{\circ}\right)$. 
nerve palsy were not observed. At the last follow-up, the mean ASES score had improved to $85.4 \pm 2.1$ and the mean VAS score improved to $3.2 \pm 1.3$. Also, at last follow-up, the mean neck shaft angle was $134.8^{\circ}$ and a mean neck shaft angle change was $3.8^{\circ}$ in 12 of the patients (75.0\%). In 5 patients (31.3\%), an unsatisfactory recovery of the range of motion was observed with less than $100^{\circ}$ of active flexion; in addition, the associated neck shaft angles were below $120^{\circ}$. Pseudoparalysis was observed in one patient in whom the neck shaft angle was measured to be less than $100^{\circ}$. In that patient, reverse total shoulder arthroplasty was performed at 3 months postoperatively.

\section{Discussion}

Proximal humerus fractures account for approximately 5\% of all limb fractures and about 10\% of total fractures in elderly patients over 60 years of age, and the incidence rate is gradually increasing. ${ }^{15)}$ Some studies have reported no difference in the degree of pain and shoulder function, regardless of whether the patients underwent surgical or non-surgical treatment. However, it is generally accepted that about $20 \%$ of cases are unstable and require surgical treatment. Gerber et al. ${ }^{16)}$ reported that the incidence of avascular necrosis of the humeral head without anatomic reduction after proximal humeral fracture could increase. The indications for surgical treatment include a single fracture of the greater tuberosity with more than $5 \mathrm{~mm}$ displacement, Neer classification 3- and 4- part fractures, more than 100\% displaced fracture of the surgical neck, more than a $40^{\circ}$ varus angle, and an anatomical neck fracture of the humerus. As yet, there is no established treatment for such fractures, so various surgical methods, such as percutaneous pin fixation, intramedullary nailing, and plate fixation technique are performed according to the surgeon's preference. There is also a suggestion that immediate replacement of the humeral head via hemiarthroplasty is needed because of the high incidence of complications such as avascular necrosis of humeral head and fracture site collapse, and, in elderly patients with osteoporosis, it is difficult to obtain satisfactory results with internal fixation due to poor bone quality. On the other hand, Gradl et al. ${ }^{17)}$ reported that, if complications can be avoided, internal fixation using a locking plate could yield better functional outcomes than those from hemiarthroplasty. Fankhauser et al. ${ }^{18)}$ reported good results in all fractures of the proximal humerus with internal fixation using a locking plate. Kontakis et al. ${ }^{19)}$ reported that if hemiarthroplasty is performed immediately after fracture, complications such as aseptic implant loosening, dislocation, infection, periprosthetic fracture, and dissociation of rotator cuff due to heterotopic ossification could occur. Additionally, in the elderly, implant mispositioning, increasing degree of tuberosity displacement, or even neurological deficit persistence may occur, which can be factors related to a poor outcome. ${ }^{20)}$
The deltopectoral and deltoid splitting approaches are widely used as surgical approaches in plate fixation. ${ }^{9)}$ The deltopectoral approach can preserve the function of the deltoid muscle and has the advantage of allowing direct observation of the fracture site, especially the surgical neck and lesser tuberosity. However, it requires a lot of soft tissue dissection, difficult manipulation of the greater tuberosity fracture fragment, and dissection of the deltoid insertion site. The deltoid-splitting approach has the advantages of minimizing soft tissue detachment, minimizing damage to the vascular supply such as the humeral circumflex artery, and facilitating manipulation of the greater tuberosity fragment. However, it also has some disadvantages: 1) the deltoid muscle is inevitably damaged during approach, 2) reduction of the fracture site may be insufficient due to the indirect visualization of the surgical neck portion, and 3) axillary nerve injury is a possibility when the plate is inserted.

In our cases, the deltoid-splitting approach was used for two main reasons. The first is that it lowers the possibility of avascular necrosis of the humeral head by avoiding direct exposure of humeral neck portion where the humeral circumflex artery originates from the humeral shaft to the head, and it preserves the periosteal blood supply by using MIPPO with little soft tissue detachment. Second, because of the nature of this approach, we could directly view the greater tuberosity fracture fragment and easily insert the allograft strut into the greater tuberosity fracture gap without applying much humeral head traction. Although our cases have relatively short-term follow-up periods, our choice of approach seems to be somewhat related to the lack of avascular necrosis in our series.

The currently preferred method of surgical treatment of proximal humeral fractures is the use of an anatomical locking plate. It can be used as a bridging plate to preserve the blood supply to the fractured bone and can provide stability for improved fixation in osteoporotic bone. In addition, it can minimize complications in unstable proximal humeral fractures which have medial column comminution. Panchal et al. ${ }^{11)}$ reported that using a locking compression plate after endosteal insertion of a fibula strut allograft in unstable proximal humerus fracture can give good results with firm medial support. Hsiao et al. ${ }^{211}$ emphasized the importance of intramedullary support for the proximal humeral fractures fixed with a locking plate under cyclic loading, especially in poor quality bone.

Surgical treatment of osteoporotic proximal humerus fractures in the elderly can lead to complications such as varus collapse, screw cutout, and avascular necrosis. In order to prevent such complications, internal fixation with a fibula strut allograft is reported to be successful. ${ }^{22-24)}$ The strut allograft may minimize postoperative varus collapse, or osteonecrosis by increasing the biomechanical strength of the construct and by resisting a loss of reduction. Revascularization of a humeral head that was ischemic at the time of injury may be achieved by maintaining frac- 

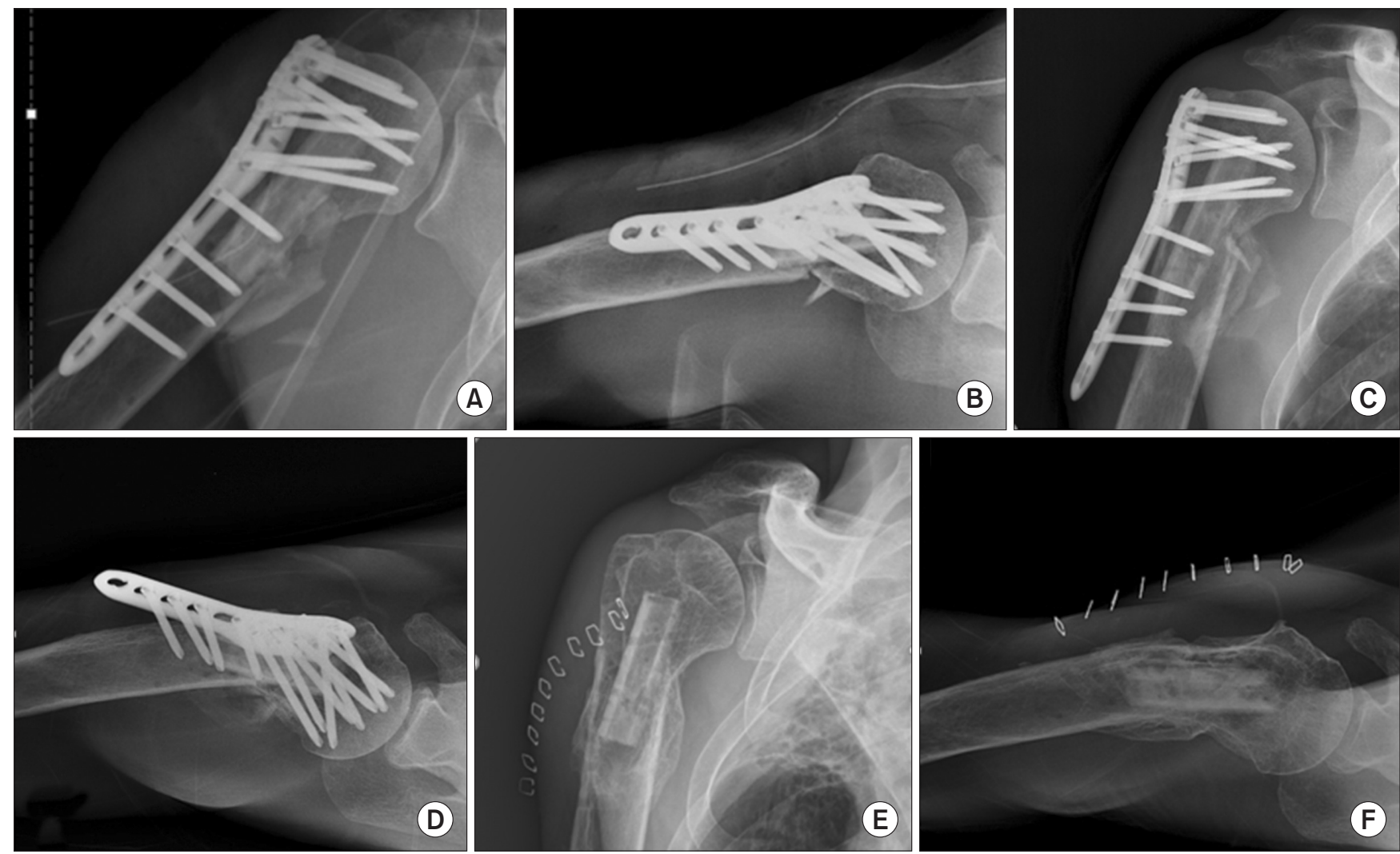

Fig. 5. A case of the role of mechanical support of the strut allograft. A 68-year-old male patient underwent surgery using our minimally invasive percutaneous plate osteosynthesis method. (A, B) Surgical outcome was radiologically satisfactory immediately after surgery. (C, D) Radiographs showing implant failure at the patient's 3-month follow-up. However, bone union was finally obtained due to the mechanical supporting role of the fibula strut allograft buttress. (E, F) Images are radiographs after metal removal operation at the 12-month follow-up.

ture reduction. Gardner et al. $^{25)}$ reported on the advantages of using strut allografts to prevent varus misalignment, obtain a solid medial support, and facilitate fracture reduction. Recently, Cha et al. ${ }^{26)}$ reported that the use of a locking plate with an endosteal strut allograft could not only maintain the neck shaft angle and the height of the head of the humerus but could also antagonize internal fixation failure compared with the use of only a locking plate in the treatment of comminuted proximal humeral fractures. Neviaser et al. ${ }^{27)}$ reported that the use of it was significantly lower in the incidence of fixation failure rate, screw cutout, and avascular necrosis of the humeral head. In their cadaveric study, Chow et al. ${ }^{28)}$ reported that augmentation using a fibular strut allograft was more resistant to repeated varus stress than that in non-strut patients. The mechanical support of a strut allograft makes it possible for patients to permit early motion and rapid rehabilitation because of its provision of immediate structural continuity and stability at the fracture site (Fig. 5). Furthermore, the use of strut allographs may also provide some osteogenic potential when used as an intramedullary bone graft even though, there is some concern about slow revascularization of the dead graft by creeping substitution or graft resorption.

In our cases, surgical methods providing the advantages mentioned above were used, and the surgical and follow-up results were as good as those presented in previous reports. ${ }^{11,29)}$ However, there are limitations to our study. First, this was a retrospective case series rather than a comparative analysis, and second, the follow-up period was insufficient to assess avascular necrosis of humeral head.

\section{Conclusion}

A minimally invasive fixation method using a locking compression plate after insertion of an endosteal fibula strut allograft in elderly patients with Neer classification 3- or 4-part fractures and severe osteoporosis can achieve good clinical results.

\section{References}

1. DePalma AF. The classic. Origin and comparative anatomy of the pectoral limb. Surgery of the shoulder. Philadelphia (PA): Lippincott Williams \& Wilkins; 1950:1-14. Clin Orthop Relat Res. 2008;466(3):531-42.

2. Rangan A, Handoll H, Brealey S; PROFHER Trial Collaborators, et al. Surgical vs nonsurgical treatment of adults with displaced fractures of the proximal humerus: the PROFHER randomized clinical trial. JAMA. 2015;313(10):1037-47. 
3. Beks RB, Ochen Y, Frima $\mathrm{H}$, et al. Operative versus nonoperative treatment of proximal humeral fractures: a systematic review, meta-analysis, and comparison of observational studies and randomized controlled trials. J Shoulder Elbow Surg. 2018;27(8):1526-34.

4. Murray IR, Amin AK, White TO, Robinson CM. Proximal humeral fractures: current concepts in classification, treatment and outcomes. J Bone Joint Surg Br. 2011;93(1):1-11.

5. Maier D, Jaeger M, Izadpanah K, Strohm PC, Suedkamp NP. Proximal humeral fracture treatment in adults. J Bone Joint Surg Am. 2014;96(3):251-61.

6. Caforio M, Maniscalco P. The importance of early rehabilitation in proximal humeral fracture: a clinical trial of efficacy and safety of a new endomedullary nail. J Back Musculoskelet Rehabil. 2017;30(2):195-202.

7. Park JY, An JW, Oh JH. Open intramedullary nailing with tension band and locking sutures for proximal humeral fracture: hot air balloon technique. J Shoulder Elbow Surg. 2006;15(5):594-601.

8. Wu CH, Ma CH, Yeh J, Yen CY, Yu SW, Tu YK. Locked plating for proximal humeral fractures: differences between the deltopectoral and deltoid-splitting approaches. J Trauma. 2011;71(5):1364-70.

9. Shin YH, Lee YH, Choi HS, Kim MB, Pyo SH, Baek GH. A modified deltoid splitting approach with axillary nerve bundle mobilization for proximal humeral fracture fixation. Injury. 2017;48(11):2569-74.

10. Sohn HS, Shin SJ. Minimally invasive plate osteosynthesis for proximal humeral fractures: clinical and radiologic outcomes according to fracture type. J Shoulder Elbow Surg. 2014;23(9):1334-40.

11. Panchal K, Jeong JJ, Park SE, et al. Clinical and radiological outcomes of unstable proximal humeral fractures treated with a locking plate and fibular strut allograft. Int Orthop. 2016;40(3):569-77.

12. Gardner MJ, Weil Y, Barker JU, Kelly BT, Helfet DL, Lorich DG. The importance of medial support in locked plating of proximal humerus fractures. J Orthop Trauma. 2007;21(3):185-91.

13. Mehta S, Chin M, Sanville J, Namdari S, Hast MW. Calcar screw position in proximal humerus fracture fixation: don't miss high! Injury. 2018;49(3):624-9.

14. Paavolainen P, Björkenheim JM, Slätis P, Paukku P. Operative treatment of severe proximal humeral fractures. Acta Orthop Scand. 1983;54(3):374-9.

15. Palvanen M, Kannus P, Niemi S, Parkkari J. Update in the epidemiology of proximal humeral fractures. Clin Orthop Relat Res. 2006;442:87-92.

16. Gerber $\mathrm{C}$, Hersche $\mathrm{O}$, Berberat $\mathrm{C}$. The clinical relevance of posttraumatic avascular necrosis of the humeral head. J Shoulder Elbow Surg. 1998;7(6):586-90.
17. Gradl G, Dietze A, Kääb M, Hopfenmüller W, Mittlmeier T. Is locking nailing of humeral head fractures superior to locking plate fixation? Clin Orthop Relat Res. 2009;467(11):2986-93.

18. Fankhauser F, Boldin C, Schippinger G, Haunschmid C, Szyszkowitz R. A new locking plate for unstable fractures of the proximal humerus. Clin Orthop Relat Res. 2005;(430):176-81.

19. Kontakis G, Koutras C, Tosounidis T, Giannoudis P. Early management of proximal humeral fractures with hemiarthroplasty: a systematic review. J Bone Joint Surg Br. 2008;90(11):140713.

20. Esen E, Doğramaci Y, Gültekin S, et al. Factors affecting results of patients with humeral proximal end fractures undergoing primary hemiarthroplasty: a retrospective study in 42 patients. Injury. 2009;40(12):1336-41.

21. Hsiao CK, Tsai YJ, Yen CY, Lee CH, Yang TY, Tu YK. Intramedullary cortical bone strut improves the cyclic stability of osteoporotic proximal humeral fractures. BMC Musculoskelet Disord. 2017;18(1):64.

22. Bae JH, Oh JK, Chon CS, Oh CW, Hwang JH, Yoon YC. The biomechanical performance of locking plate fixation with intramedullary fibular strut graft augmentation in the treatment of unstable fractures of the proximal humerus. J Bone Joint Surg Br. 2011;93(7):937-41.

23. Krappinger D, Bizzotto N, Riedmann S, Kammerlander C, Hengg $C$, Kralinger FS. Predicting failure after surgical fixation of proximal humerus fractures. Injury. 2011;42(11):1283-8.

24. Jung WB, Moon ES, Kim SK, Kovacevic D, Kim MS. Does medial support decrease major complications of unstable proximal humerus fractures treated with locking plate? BMC Musculoskelet Disord. 2013;14:102.

25. Gardner MJ, Boraiah S, Helfet DL, Lorich DG. Indirect medial reduction and strut support of proximal humerus fractures using an endosteal implant. J Orthop Trauma. 2008;22(3):195200.

26. Cha H, Park KB, Oh S, Jeong J. Treatment of comminuted proximal humeral fractures using locking plate with strut allograft. J Shoulder Elbow Surg. 2017;26(5):781-5.

27. Neviaser AS, Hettrich CM, Beamer BS, Dines JS, Lorich DG. Endosteal strut augment reduces complications associated with proximal humeral locking plates. Clin Orthop Relat Res. 2011;469(12):3300-6.

28. Chow RM, Begum F, Beaupre LA, Carey JP, Adeeb S, Bouliane MJ. Proximal humeral fracture fixation: locking plate construct \pm intramedullary fibular allograft. J Shoulder Elbow Surg. 2012;21(7):894-901.

29. Sohn HS, Jeon YS, Lee J, Shin SJ. Clinical comparison between open plating and minimally invasive plate osteosynthesis for displaced proximal humeral fractures: a prospective randomized controlled trial. Injury. 2017;48(6):1175-82. 